\title{
The challenges in caring for morbidly obese patients in Intensive Care: A focused ethnographic study
}

Dr Caz Hales, Dr Maureen Coombs, Dr Kay de Vries

\begin{abstract}
Background: Critically ill morbidly obese patients pose considerable healthcare delivery and resource utilisation challenges. However little is known about the care of these patients in intensive care.

Objective: To explore medical and nursing practices and attitudes in intensive care when caring for critically ill morbidly obese patients.

Methods: A focused ethnographic approach was adopted. Participant observation of care practices and interviews with intensive care doctors and nurses were undertaken over a four month period. Qualitative analysis was conducted using constant comparison.
\end{abstract}

Setting: An 18 bedded tertiary intensive care unit in New Zealand.

Participants: Sixty-seven intensive care nurses and 13 intensive care doctors involved with the care and management of seven critically ill patients with a body mass index $\geq 40 \mathrm{~kg} / \mathrm{m} 2$.

Findings: Morbidly obese patients present significant physical and language challenges for intensive care practice. The physical shape of morbidly obese patients did not appropriately fit the different equipment used. Staff used specific knowledge of the patient's body size and shape to adapt care practices and keep patients safe and comfortable. There were also specific language challenges where staff expressed concern about what words were most appropriate to use to describe body mass when in the presence of morbidly obese patients.

Conclusions: Bariatric care pathways need to be developed that use more suitable body measurements to inform the use of bariatric equipment. Intensive care staff need to engage in debate about what is acceptable, respectful, and appropriate language in the delivery of bariatric patient care.

\section{Introduction}

Obesity has become a common condition in many countries, and a global focus for public health.1,2 Obesity is of particular concern in New Zealand with $31 \%$ of adults identified as obese with significantly higher prevalence of $46 \%$ and $67 \%$ in Maori and Pacific adult populations, respectively. 3 Morbid obesity is the fastest growing category of obesity in developed countries.4, 5 This is significant given the particular health care needs of this population. Morbid obesity is classified as a body mass index (BMI) of greater or equal to $40 \mathrm{~kg} / \mathrm{m2}$. BMI, a measure of weight adjusted for height, is the most commonly used indirect method to assess body fat.2,6 BMI categorises obesity into different levels and identifies the risks of co-morbidities associated with each. An indirect measure of Q7 obesity, BMI has been highly criticised for: its inability to differentiate between fat and lean mass; provide information on the distribution of body fat; and incorporate the variations in the ratio of fat to lean mass in different ethnicities.6,8 Waist circumstance, and waist:hip ratios are used to complement clinical data regarding fat distribution and health risk.6,7 The critically ill morbidly obese patient places specific demands on intensive care services as a result of: prolonged mechanical ventilation needs and tracheostomy tube placement; 9,10 increased length of intensive care stay 11,12; and increased respiratory and wound complications.9,13 This requires increased staffing support and specialist bariatric equipment.14 Despite these frequently cited challenges, the current intensive care literature provides little, if any, detail on how the size and shape of the 
morbidly obese patient challenges everyday intensive care practice. Furthermore, whilst there is evidence of the presence of weight bias in healthcare and the negative attitudes held towards obese and morbidly patients,15,16 no studies explore this area in the intensive care setting. This is the second paper reporting findings from a study that explored how doctors and nurses in intensive care perceive and manage critically ill morbidly obese patients. Our first paper focused on the findings of how socially awkward moments, caused by social stigma, between staff and morbidly obese patients during care were managed.17 In this paper we report findings on the physical challenges of caring for morbidly obese patients and language challenges that pre-empted social awkwardness observed when caring for this patient population.

\section{Methods}

Using focused ethnographic methods, this study adopted a social constructivist paradigm that acknowledges social reality is constructed by and between individuals, who generate their knowledge and meaning from their experiences and ideas.18,19 Focused ethnography enables a distinct issue or shared experience within a culture or specific setting to be explored.20,21 Attention is focused on the specific activities and shared features of individuals in the subgroup when engaged in practices related to the distinct issue.20,21 This approach enabled the study's aim of understanding the 'situated' experiences of intensive care staff providing care to a subgroup of patients who were morbidly obese, to be met. Ethnographic data collection methods of participant-observation and single face-to-face interviews were conducted. An insider perspective was adopted for this study as the primary researcher $(\mathrm{CH})$ worked in the study site, and had done so for the previous seven years. The insider position is often the approach used by nurse researchers when researching not only their own specialty practice area but also their own workplace.22-25 The knowledge and pre-existing relationships of this insider position were used to inform field work. The first author has been closely involved in the challenges of risks and other care issues for critically ill patients, particularly those people who are morbidly obese, and is a specialist educator in the fields of critical care and bariatric nursing. The second and third authors were her research supervisors. The study setting was an 18 bedded tertiary intensive care unit (ICU) in New Zealand. Participants were ICU doctors and nurses who cared for obese patients in this unit. All ICU staff were invited to participate. Staff caring for morbidly obese patients, who were not undergoing weight loss surgery and expected to remain in the unit for more than $12 \mathrm{~h}$, were observed. Informed written consent was obtained from all participants. Staff were consented prior to the data collection period whilst patients were consented to be observed at the time of data collection. For patients who were unconscious and ventilated, a family assent form was signed and retrospective consent sought from the patient. All patients were deemed to be mentally competent by the intensivist on duty and were cognitive of their surroundings at the time of consent. Eight patients were identified as eligible for the study, of which seven consented. The other eligible patient was unconscious on admission, and the severity of his head injury and the potential for him to never be in a position to formally consent was of concern. Therefore, the enrolment process was not pursued. No participants withdrew consent during the study. Over a period of four months, ethnographic fieldwork techniques of participant observation and ethnographic interviews were conducted. The 'observer as participant' role, 26 was adopted during the fieldwork, where observation was favoured over participation. 27 
Table 1

Data sources.

Participants $\mathrm{n}=80$

Nursing staff

- $\quad$ Nurses observed in practice and interviewed 25

- $\quad$ Nurses observed only 28

- Nurses interviewed only

Medical staff

- $\quad$ Doctors observed in practice only 8

- Doctors observed in practice and interviewed

Observations of staff occurred in all clinically designated areas of the unit and the staff room. The primary focus of the observations included: handovers and ward rounds, personal cares, and conversations between staff, and staff and patients. Interviews were conducted by the primary author and focused on four key areas: nurses' and doctors' experiences of caring for morbidly obese patients; personal thoughts and beliefs about obesity; resources and education opportunities about care and management of morbidly obese patients; and specific questions regarding interactions observed in the field. Interviews were audio-taped and transcribed verbatim. Analysis of the data was conducted in three stages using the constant comparison technique28:'deconstruction' where data was systematically broken down into concepts29; 'construction', where the concepts were reassembled into a new 'second order'30; and 'confirmation' where the conceptualisation was constructed into a descriptive narrative. 31 Analysis of the data was conducted by the primary author and verified by the second and third authors. Findings were discussed with a sample of the study participants to enable further verification. Due to the dual identity of the primary author as a senior nurse and researcher at the study site, the role and expectations of the researcher with regards to safeguarding patients from harm were agreed by the nursing and medical leads at the hospital. How and when the researcher would intervene if a patient's welfare and safety was compromised, were agreed and communicated to all participants. Direct patient care was not undertaken by the researcher. Ethical approval was given by Health and Disability Ethics Committee of New Zealand (Approval CEN09/06/033).

\section{Findings}

Sixty-seven registered nurses, 13 doctors and seven patients participated in the study (Table 1). One hundred and sixty seven hours of patient observation was undertaken over 21 days with an average of 12-16 h per day. Interviews lasted between 20-80 min. Pseudonyms are used in all data excerpts. Two themes were developed from the data. These identified that morbidly obese patients presented significant physical, and language challenges for ICU practice.

\section{Physical challenges}

The physical body of morbidly obese patients presented specific care challenges in ICU. This was because weight and not physical shape of the patient was used to assess the equipment required to nurse the patient. With the exception of the standard ICU bed (safe carrying capacity $267 \mathrm{~kg}$ ), the 
weight limit of standard nursing care in ICU at the time of the study was $150 \mathrm{~kg}$. Beyond this weight, specialised equipment, such as the commode and shower trolley, had to be resourced from a central equipment store or hired from an equipment company or the fully equipped bariatric ICU isolation room (weight capacity of $500 \mathrm{~kg}$ ) utilised. The weight range of patients in this study was $122-167 \mathrm{~kg}$, with a BMI range of $40-61 \mathrm{~kg} / \mathrm{m} 2$ and all patients were cared for on a standard ICU bed within the main area of the ward. In using this weight based assessment, all morbidly obese patients were within the weight limits of standard ICU equipment with specialised bariatric equipment being used. However, the specific size and body shape of these patients meant that this equipment was not tailored for the specific contours of obese patients. The different body shapes of morbidly obese patients made the fit with standardised equipment difficult. Beds were often too narrow, the seat width of chairs and commodes too small, hoist slings too tight and stretchers too unsteady to support the different physical body shapes. Not only did this impact on patient safety, but also on patient comfort:

Folds of skin overhung the chairs and commodes and the hoist sling dug into and pinched the skin folds on her large oedematous thighs which caused discomfort, sometimes pain, and marking of skin (Agnes-patient, field notes).

Staff recognised that care of morbidly obese patients posed significant physical challenges beyond the issue of patient weight:

It wasn't a weight limitation. It was a physical [one].. . . physically we couldn't gather him together enough to fit him inside the [CT] scanner (John-doctor, interview).

Due to the different body shapes, equipment was often ill fitting and inappropriate for the patient's size and body shape. The ergonomic design of the beds created specific issues in practice. The distributed body weight of the patient over the motorised section of the beds caused frequent failures of the backrest, particularly in patients with large adipose deposits around their abdomen.

On many occasions the motorised bed failed to lift the backrest up to position Rawiri into a seated position. This failure appeared to be caused by the bulk of his $132 \mathrm{kgs}$ resting on the motorised section of the bed (Rawiri-patient, field notes).

The position at which the back rest of the bed was placed to enable patients to sit in an upright position was problematic. Sitting patients up in these beds often increased the risk of physiological compromise of the patient:

You can't position them in the bed because if you sit them up their stomach presses up on their lungs (Yvonne-nurse, interview).

This resulted in the patient's body shape and size being used to inform patient care instead of the patient's weight. For example, patients with several large and loose skin rolls were particularly challenging for turning and positioning. When lying on their sides it was often difficult to find an optimal position that relieved pressure contact with the bed: "[They were] difficult to balance on their side. . difficult to stop the momentum once you start moving them" (Rebecca-nurse, interview) and "you don't actually get them off their pressure area[s]" (Phillippe-nurse, interview). This resulted in extra nurses required for safe turning. In contrast, those morbidly obese patients who had firmer, bulky, or more solid bodies were less challenging to position and move about the bed:

Quite tight bodies, you can turn them quite easily... you can get a better turn because you're actually moving their whole body (Phillippe-nurse, interview). 
Staff used specific knowledge ofthe patient's obese body to support and adapt care practices. This often required improvisation to accommodate the morbidly obese body morphologies. Staff were observed to physically manoeuvre the patient's body into equipment to ensure a fit: "I was having to prop her physically onto the stretcher with my knees because I was worried she was going to fall off." (Shirley-nurse, interview) and modify available equipment to create more room to accommodate the physical body. This included use of additional supports for overhanging body parts: "bedside tables at the height of the bed with pillows on were used as a ledge on the side of the bed" (Rose-nurse, interview) or use of equipment to create wider spaces:

Her legs were too short for the depth of the seat and her thighs and stomach overhung the armrests. To overcome these problems the leg rest was raised to support her legs, and pillows were placed under her bottom to raise the height of the seat level with that of the arm rests creating a wider seat (Agnes-patient, field notes).

Language challenges

How staff talked about the physical size of the morbidly obese patient and the language used was challenging. It was the lack of an agreed and acceptable language to describe patients that led to an awkwardness in patient-staff interactions. Staff were divided in whether they would or would not use the terms 'obese' and 'fat' in practice: "Within earshot of the patient I talk about obesity and I don't generally tend to use the word fat" (George-nurse, interview), "I'd use the word fat rather than obese" (Helen-nurse, interview). Staff were reluctant to use biomedical terminology, such as obese and morbid obesity, when with a patient, due to personally held beliefs about society's negative connotations of these terms:

We are generally uncomfortable of the societal associations of the word obese [and] the associations that people have with obese people. Once you use that label then the patient may find it offensive (John-doctor, interview).

Similarly, staff did not want to appear judgemental when talking about the patient's size: "Obese has a big subjective element to it. It's not just passing on information, it's actually passing on judgement (David-doctor, interview). Equally, personal feelings and interpretations of the terms affected the terms used in practice: 'I'd be mortified [being] described as morbidly obese in the bed, it would be awful so that's why I wouldn't use that' (Vicki-nurse, interview).

It's actually a lot worse to call someone obese than just fat. . obese is more of a dramatic term of saying you're beyond fat and morbidly obese, it's like hammering the nail in the coffin (Lee-nurse, interview).

Past experiences using biomedical language affected staff's decisions on what language to use specifically as patients, themselves, disliked the word 'obese': A friend of mine had called a patient obese in her nursing notes and the patient read the notes and was massively offended by it" (Florence-nurse, interview). In conversations with Gary he stated "that he didn't mind being called 'the big fellow' or 'fat guy' but really hated and was offended by the word 'obese'" (Gary-patient, field notes). When staff spoke about the physical size of the patient, the most commonly used terms were high/increased BMI, bariatric, obese, fat and overweight. In situations where the patient was awake and might hear the conversation staff were more likely to avoid using these words: When they're awake people [nurses] are embarrassed to say this person is morbidly obese. You don't want to turn round and say 'oh this woman's morbidly obese or they're a little bit fat'. You don't want to ruin your relationship that you've built by saying that (George-nurse, interview). The stigmatisation associated with use of biomedical obesity language and the uncertainty about how staff can talk 
about the morbidly obese body has prevented the development of an appropriate vocabulary to describe the physical obese body and the challenges posed during care.

\section{Discussion}

\section{Physical care}

Morbidly obese patients posed significant clinical challenges for the ICU team. Literature to date has previously described the physical and physiological sequelae for critically ill obese patients in ICU.9,32-34 Findings from this study identify how ICU staff use specific knowledge of body shape, size, and type of body to inform provision of physical care needs for critically ill obese patients. Measurements such as patient weight or BMI often did not inform patient management. More importantly, shape and size were key determining factors for direct patient care and guided individual patient management strategies. Staff used this knowledge to adapt care practices to those which were more in fitting with the needs of specific obese body morphologies. To date, the subject of the physical size and shape of obese patients in the hospital setting has not been well explored in the literature. One exception is the study by Merrill and Grassley35 who identified that the physical environment of clinics and examination rooms created physical care challenges for obese women seeking healthcare. In their study, obese women did not fitinto normal healthcare spaces because of their size and weight. As in the ICU setting, bariatric sized chairs, examination gowns, and other equipment e.g. blood pressure cuffs were found to be too small or ill-fitting for the patient's physical shape and size. 35 In this study, a significant care issue resulted from the design of the bariatric equipment used. Bariatric equipment appeared to be designed by scaling up standard patient equipment. For examples, beds and chairs are made proportionally larger. However, bariatric patients are not simply proportionally larger than 'standardised' patients. Weight distributed in certain areas meant that, whilst patients could sit comfortably in the width of a chair, the depth of the chair was too deep. Similar design issues have been raised in Forhan et al.'s36 study where access to lifts, narrow staircases and stairs, without sufficient depth to every step, were particularly problematic for obese patients. To date, there is limited empirical work that addresses the design of the equipment where obese patients are the participants of the study and is an area needing serious consideration.

\section{Language}

Talking about the difficulties that the obese body posed, was awkward for ICU staff. There was a lack of meaningful language to describe the specific issues of caring for the obese body, and staff found using the terms 'obese' and 'fat' particularly problematic. This was, in part, due to the negative societal associations attached to these words, and that the words themselves did not adequately define the care challenges. Concerns about the use of terminology when discussing the topic of obesity with patients have been reported in other research,16,37-39 with the terms 'obese' and 'fat' identified as the least desirable words for health professionals to use.16,39,40 However, much of this work on acceptable terminology has focused on the words used to initiate weight loss management conversations and not on how to discuss the physical size and shape of the obese body in clinical practice. This has left a significant gap for health care professionals in what is appropriate language to describe the issues of shape and size of the obese patient. To date there has been no consensus about the preferred or correct terms that health care professionals should use when discussing the topic of obesity.16,39 It is important to find language that will allow the care challenges of the morbidly obese body to be accurately defined and described whilst at the same time minimising the risk of causing offence to the patient 


\section{Limitations}

The aim of this study was to understand the 'situated' experiences of the ICU staff when engaging in the care of critically ill morbidly obese patients. This was achieved through focusing on issues and experiences of staff in delivering care to morbidly obese ICU patients. Quality checks and detailed audit trials further enhanced the study rigour. Interviews with morbidly obese ICU patients could provide a more holistic understanding of care practices. Ethnographic inquiry acknowledges that the very act of observing or focusing attention on a particular aspect of behaviour can sensitise and alter that behaviour. Therefore, behaviour changes observed during the study may in part be both natural and/or as a result of focused observation where many participants entered into their own reflexive process. Another limitation of this study was the use of one study site thereby limiting transferability of findings. By using one site, this ethnographic research offers depth rather than breadth of understanding in caring for critically ill morbidly obese patients.

\section{Conclusion}

To address the practice challenges of caring for morbidly obese patients in ICU development of bariatric care pathways are required that are underpinned by suitable and meaningful body measurements to appropriately assess the fit between the patient's size and shape and equipment used. The development of assessment tools and admission to discharge pathways that are based on shape, size and types of bodies are essential to improving the quality of care for this patient population. There is a need to engage in open debate about what is acceptable, respectful, appropriate and meaningful language in the delivery of patient care. In doing so, we need to understand the impact of the language we use during patient care and develop appropriate language that is meaningful to the care interaction.

Authors' contributions C.H. conceived the study, collected the data, analysed the data, interpreted the data and wrote the manuscript. K.D.V. and M.C. supervised the study and had critical input into the manuscript writing and revisions. All authors agreed the final paper.

\section{Conflicts of interest None.}

Funding This study was partially funded by a Victoria University of Wellington, New Zealand Faculty Postgraduate Research grant (Grant Number 97578). Acknowledgements The authors wish to sincerely thank the participants who were willing to share their experiences and be observed in practice.

\section{References}

1. Ministry of Health. Tracking the obesity epidemic: New Zealand 1977-2003. Wellington, New Zealand: Ministry of Health; 2004.

2. Sassi F. Obesity and the economics of prevention: fit not fat. Organisation of Economic Co-operation and Development; 2010.

3. Ministry of Health. New Zealand Health Survey: Annual update of key findings 2014/15. Wellington, New Zealand: Ministry of Health; 2015.

4. Bromley C, Given L. Scottish health survey 2010. Scotland: Scottish Centre for Social Research; 2011. 
5. Grieve E, Fenwick E, Yang HC, Lean M. The disproportionate economic burden associated with severe and complicated obesity: a systematic review. Obes. Rev 2013;14(11):883-94.

6. Ministry of Health. Clinical guidelines for weight management in New Zealand adults. Wellington, New Zealand: Ministry of Health; 2009.

7. World Health Organisation. Obesity: preventing and managing the global epidemic. Geneva: WHO; 2000.

8. Prentice AM, Jebb SA. Beyond body mass index. Obes. Rev 2001;2(3):141-7.

9. Villavicencio MA, Sundt TA, Daly RC, Dearani JA, McGregor CG, Mullany CJ, et al. Cardiac surgery in patients with a body mass index of 50 or greater. Ann. Thorac. Surg 2007;83:1403-11.

10. Westerly BD, Dabbagh O. Morbidity and mortality characteristics of morbidly obese patients admitted to hospital and intensive care units. J. Crit. Care 2011;26(2):180-5.

11. Martino JL, Stapleton RD, Wang M, Day AG, Cahill NE, Dixon AE, et al. Extreme obesity and outcomes in critically ill patients. CHEST J 2011;140(5):1198-206.

12. Sakr Y, Elia C, Mascia L, Barberis B, Cardellino S, Livigni S, et al. Being overweight or obese is associated with decreased mortality in critically ill patients: a retrospective analysis of a large regional Italian multicenter cohort. J. Crit. Care 2012;27(6):714-21.

13. Yaegashi M, Jean R, Zuriqat M, Noack S, Homel P. Outcome of morbid obesity in the intensive care unit. J. Intensive Care Med 2005;20(3):147-54.

14. Winkelman C, Maloney B. Obese ICU patients: resource utilization and outcomes. Clin. Nurs. Res 2005;14(4):303-23.

15. Puhl RM, Heuer CA. The stigma of obesity: a review and update. Obesity 2009;17(2):941-64.

16. Swift JA, Choi E, Puhl RM, Glazebrook C. Talking about obesity with clients: preferred terms and communication styles of U.K. pre-registration dieticians, doctors, and nurses. Patient Educ. Couns 2013;91(2):186-91.

17. Hales $\mathrm{C}$, de Vries $\mathrm{K}$, Coombs MA. Managing social awkwardness when caring for morbidly obese patients in the intensive care: a focused ethnography. Int. J. 
Nurs. Stud 2016;58:82-9.

18. Koro-Ljungberg M, Greckhamer T. Strategic turns labeled 'ethnography': from description to openly idealological productions of culture. Qual. Res $2005 ; 5(3): 285-306$.

19. Lincoln SY, Lynham SA, Guba EG. Paradigmatic controversies, contradictions, and emerging confluences revisited. In: Denzin NK, Lincoln YS, editors. The SAGE handbook of qualitative research. 4th ed. London: SAGE Publications; 2011. p. 97-128.

20. Higginbottom GM, Pillay JJ, Boadu NY. Guidance on performing focused ethnographies with an emphasis on healthcare research. Qual. Rep 2013;18(Art.

17):1-16.

21. Cruz EV, Higginbotton $\mathrm{G}$. The use of focused ethnography in nursing research. Nurse Res 2013;20(4):36-43.

22. Asselin ME. Insider research: issues to consider when doing qualitative research in your own setting. J. Nurses Staff Dev 2003;19(2):99-103.

23. Cudmore $\mathrm{H}$, Sondermeyer J. Through the looking glass: being a critical ethnographic researcher in a familiar nursing context. Nurse Res 2007;14(3):25-35.

24. Griffiths P. Ethical conduct and nurse ethnographer: consideration of an ethic of care. J. Res. Nurs 2008;13(4):350-61.

25. Simmons M. Insider ethnography: tinker, tailor, researcher or spy? Nurse Res 2007;14(4):7-17.

26. Gold R. Roles in sociological field observation. Soc. Forces 1958;36(3):217-23.

27. Hammersley M, Atkinson P. Ethnography: principles in practice. 3rd ed. London: Routledge; 2007.

28. Glaser BG, Strauss AL. The discovery of grounded theory: strategies for qualitative research. Chicago: Aldine; 1967.

29. Gobo G. Doing ethnography. London, England: SAGE Publications; 2008.

30. Van Maanen J. Qualitative methodology. London: SAGE Publications; 1979.

31. Strauss AL, Corbin J. Basics of qualitative research. Thousand Oaks: SAGE Publications; 1990.

32. Gallagher-Camden S. Nursing care of the bariatric patient. Bariatr. Nurs. Surg. 
Patient Care 2006;1(1):21-30.

33. Lewandowski K, Lewandowski M. Intensive care in the obese. Best Pract. Res. Clin. Anaesthesiol 2011;25(1):95-108.

34. Jamadarkhana S, Mallick A, Bodenham AR. Intensive care management of morbidly obese patients. Contin. Educ. Anaesth. Crit. Care Pain 2014;14(2):73-8.

35. Merrill E, Grassley J. Women's stories of their experiences as overweight patients. J. Adv. Nurs 2008;64(2):139-46.

36. Forhan MA, Law MC, Vrkljan BH, Taylor VH. The experience of participation in everyday occupations for adults with obesity. Can. J. Occup. Ther $2010 ; 77(4): 210-8$.

37. Dutton GR, Tan F, Perri MG, Stine CC, Dancer-Brown M, Goble M, et al. What words should we use when discussing excess weight? J. Am. Board Fam. Med 2010;23(5):606-13.

38. Wadden TA, Didie E. What's in a name? Patients' preferred terms for describing obesity. Obes. Res 2003;11(9):1140-6.

39. Gray CM, Hunt K, Lorimer K, Anderson AS, Benzeval M, Wyke S. Words matter: a qualitative investigation of which weight status terms are acceptable and motivate weight loss when used by health professionals. BMC Public Health 2011;11(1):1-9.

40. Weight Concern. Obese and fat are the most hurtful words a doctor can use; 2008 http://www.shape-up.org/weightcon/WCNletterSpring08.pdf. 